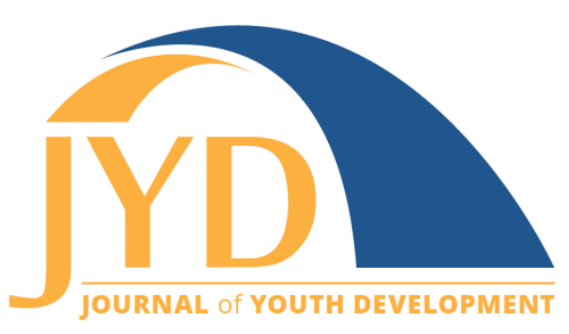

http://jyd. pitt. edu/ | Vol. 14 Issue 1 DOI 10.5195/jyd.2019.671 | ISSN 2325-4017 (online)

\title{
Competitive Readiness: Developmental Considerations to Promote Positive Youth Development in Competitive Activities
}

\author{
Jillian Kochanek \\ Michigan State University \\ kochane2@msu.edu
}

Alysha Matthews

Michigan State University

matth287@msu.edu

Emily Wright

Michigan State University

wrigh694@msu.edu

Justin DiSanti

Michigan State University

disantij@msu.edu

\section{Michelle Neff}

Michigan State University

hydemich@msu.edu

\section{Karl Erickson}

Michigan State University kte@msu.edu

\begin{abstract}
Competitive experiences have the potential to empower youth. Understanding the conditions under which young people can grow through competition is necessary to identify how competitive experiences can optimally support youth as engaged participants and people. This paper serves as a novel integration of previous research aimed toward practitioners. The purpose of this paper is to provide adult (and youth) leaders with empirically-based, practically meaningful guidance to integrate practices that support
\end{abstract}

(cc) $\mathbf{E Y}$ New articles in this journal are licensed under a Creative Commons Attribution 4.0 License. This journal is published by the University Library System, University of Pittsburgh and is cosponsored by the University of Pittsburgh Press. The Journal of Youth Development is the official peer-reviewed publication of the National Association of Extension 4-H Agents and the National AfterSchool Association. 


\section{Competitive Readiness}

competitive readiness for youth development. To clarify the youth competitive readiness debate, this paper adopts a process-oriented, developmental perspective. We first define and provide background on youth development. Second, we put forth guiding postulates and their application to practice for organized competitive experiences for positive youth development promotion. We argue that youth are "ready" to compete not just when they can survive competitive experiences, but thrive through them. Interactions between individual, contextual, and developmental factors over time influence fluctuations in a young person's state of competitive readiness. In this way, competitive readiness is an ongoing process that encompasses the individual needs of the child in relation to the environment.

Key words: competitive readiness, youth development, competition

Competition comes from the Latin root com meaning "with" and petere meaning "to strive." The term has a cooperative essence-signifying a mutual striving with rather than against. Similarly, the scientific literature identifies competition as social comparison process with the possibility for mutual advancement (Choi, Johnson, \& Kim, 2014; Passer, 1988). Prevailing societal attitudes about competition not only glorify a win-at-all-costs mentality, but often solely equate success with beating the opponent (Gould, 2009; Shields \& Bredemeier, 2009). Organized extracurricular activities in which youth participate are hardly immune to this zero-sum worldview (Gould, 2009). In fact, performance contexts in which kids can develop varied skill sets embody this result-driven culture, and can further reinforce hyper-competitive and antagonistic ideas/practices.

Whether competition is developmentally appropriate and advantageous for youth is a contentious debate. Proponents of youth participation in competition suggest that competitive experiences are essential for kids to learn life lessons and gain "competitive kid capital" (Daniels, 2007; Friedman, 2013). For example, children acquire valuable social capital through competition: learning to internalize the importance of winning, bouncing back from losing, performing under time constraints and public scrutiny, and persisting under stress. Advocates assert that competitive experiences are vital because they prepare youth for result-driven realities of adulthood. Alternatively, critics of competition argue that hyper-competitive environments can have potential harmful consequences: competition can inhibit performance and skill development, reinforce poor social skills/behaviors, and produce maladaptive selfperceptions (Choi et al., 2014; Kohn, 1992). Thus, many critics oppose youth participation in competition during this formative developmental stage.

Despite polarized debate, the issue of if, and when, youth are ready to compete cannot be appropriately resolved with an either-or response. Competition is not inherently advantageous or disadvantageous (Shields \& Bredemeier, 2009); rather, how young people understand 


\section{Competitive Readiness}

competition and perceive competitive contexts accurately capture its developmental impact (Choi et al., 2014; Passer, 1988). Thus, competitive readiness refers to a young person's capacity to meet the demands of participation and learn values and skills (Aicinena, 1992; Harris, 2000). Youth are "ready" to compete when they can thrive through competitive experiences, not just endure (or become hardened to) harsher realities. Interactions between individual, contextual, and developmental factors over time influence fluctuations in a young person's state of competitive readiness. Therefore, competitive readiness is an ongoing process that encompasses the individual needs of the child relative to the environment.

\section{Purpose}

Competitive experiences can empower youth. Understanding the conditions under which young people can grow through competition is necessary to identify how to optimally support youth as engaged participants and people (Choi et al., 2014; Passer, 1988). Thus, this paper serves as a novel integration of previous research aimed toward practitioners. The purpose of this paper is to provide adult (and youth) leaders with empirically-based, practically meaningful guidance to help shift their thinking and applied practices to better support competitive readiness for youth development. To do so, this paper adopts a process-oriented, developmentalperspective. First, we define and give background on youth development. Next, we offer unique practicallyapplicable postulates for positive youth development promotion in activity contexts. Though guiding suggestions largely emanate from studies in youth sport-given this vast research-we intend for postulates to be integrated with care into any youth activity setting where competition is a shared feature (See Shields \& Bredemeier, 2009). Though a distinct domain, sport is not markedly more stressful than other evaluative youth development contexts (Simon \& Martens, 1979). Thus, research including-but not limited to-sport can contribute to a comprehensive understanding of youth competitive readiness.

\section{Youth Development Defined}

Youth development refers to a young person's growing capacity to understand and engage in his/her environment over time (Hamilton, Hamilton, \& Pittman, 2004). An ongoing, dynamic process, youth development constitutes more than biological maturation (Hamilton et al., 2004). The National Research Council and Institute of Medicine (2002) outlines primary areas related to this process: physical, intellectual, psychological/emotional, and social. Growth in these categories does not passively occur; rather, young people are instrumental in guiding their own developmental trajectory. Young people are optimally developing when they not only 


\section{Competitive Readiness}

invest in their own well-being, but contribute to that of others and society (Coakley, 2011). The notion of "thriving" (more than surviving) competitive experiences as the desired indicator of competitive readiness captures this positive bi-directional influence. Thriving refers to patterns of mutually beneficial person-context relations over time, whereby the developing individual and social context derive ongoing benefit (Bowers, Geldhof, Johnson, Lerner, \& Lerner, 2014). Such mutual benefit is conceptualized as the alignment of the developing young person's attributes with features of his/her context (See Benson \& Scales, 2009).

Youth development also constitutes a philosophy and practice. As a philosophy, youth development arose in reaction to earlier approaches that focused on fixing individual deficiencies (Diener, 2009). Such efforts sought to prevent and mitigate risk behaviors (i.e., ridding them of deficits). A strengths-based approach represents an alternative philosophy that examines how youth acquire skills, knowledge, and other personal/social assets to thrive (Eccles \& Gootman, 2002; Petitpas, Cornelius, Van Raalte, \& Jones, 2005). As a practice, youth development includes initiatives and institutions in varied settings in which young people engage. Neighborhoods, home, school, and cyberspace are prospective sites for youth to build competencies, socialize, and grow (Hamilton et al., 2004). Youth (ages 6 to 18) spend considerable time in organized activity settings, ranging from more, or less, competitive (Mahoney, Larson, Eccles, \& Lord, 2005). Thus, competition is one practice in which youth can engage, which has developmental implications.

\section{Positive Youth Development Through Organized Activity Participation}

Positive youth development (PYD) is an integrative framework that considers cognitive, social, emotional, and intellectual skills necessary for young people to fully function in society (Eccles \& Gootman, 2002; Larson, 2000). A PYD approach is a strengths-based approach that emphasizes life skills acquisition (Damon, 2004; Petitpas et al., 2005). Current perspectives reinforce that organized activity involvement does not automatically foster adaptive outcomes, but that programs/leaders can empower youth contingent upon individual, developmental, and environmental factors (Eccles, Barber, Stone, \& Hunt, 2003; Fraser-Thomas, Côté, \& Deakin, 2005; Gould \& Carson, 2008). Models posit that growth and life skills acquisition are most likely to occur when youth participate in developmentally appropriate settings with supportive adult mentors (Lerner et al., 2005). Salient environmental factors that impact a young person's developmental include competition, and how this contextual characteristic interacts with aspects internal and external to the individual over time determines whether competition might serve as positive developmental tool. 
Early conceptual and empirical work reflect efforts of sport psychology researchers to understand competition in youth athletes (e.g., Passer, 1988). These findings highlight individual factors (e.g., trait anxiety and enjoyment) that influence how youth interpret competition (Martens \& Gill, 1976; Scanlan \& Passer, 1978, 1979). Related research also accounts for relevant contextual factors (e.g., game outcome characteristics and social evaluation potential) that influence youth appraisals of competition within, but not exclusive to, sport (Scanlan \& Lewthwaite, 1984, 1986; Simon \& Martens, 1979). For example, Simon and Martens (1979) compared children's perceptions of their sport and/or music experiences, and found that non-sport and sport participants who engaged in contexts with high social evaluation potential similarly experienced pre-event anxiety. Interestingly, youth who engaged in solo musical performances reported the highest levels of pre-event anxiety.

Extant research also accounts for relevant factors, and their interactions, that have implications for youth participants' competitive experience and readiness. Since these early studies, however, little conceptual or empirical work has offered adult (and youth) leaders practical guidance on whether, and under what conditions, youth are "ready" to compete. As such, this paper reviews competition-oriented youth organized activity research to bring clarity to the competitive readiness debate.

\section{A Developmental Perspective}

Youth competitive readiness is a highly contested, complex topic, but studies of youth can clarify the debate and offer practical guidance. Research supports a dynamic understanding of competitive readiness, and underlines that interactions among individual, contextual, and developmental factors over time influence competitive environments and a young person's perceptions of competition. As such, this paper first offers a developmental perspective of youth (physical, cognitive, and psychosocial) maturational trends, highlighting ages 7 to 12 as a critical developmental period (See Benson, Scales, Hamilton, \& Sesma, 2006; Passer, 1988; Scanlan, 1996). Gradual exposure to competitive contexts beginning in this period can better ensure that competition enables youth to flourish (Choi et al., 2014; Passer, 1988). This developmental perspective situates explanation of guiding postulates and practical examples for leaders to use competition for PYD promotion. 


\section{Physical Maturation}

Physical growth that occurs between the ages of 7 and 12 follows a relatively consistent progression of changes (Malina, Bouchard, \& Bar-Or, 2004). Awareness of physical trends can better ensure that activity leaders appropriately expose youth to optimal challenges (Stuntz \& Weiss, 2010), which are particularly beneficial for children with low ability perceptions who are likely to avoid difficult tasks (R. E. Smith, Smoll, \& Curtis, 1979; Smoll, Smith, Barnett, \& Everett, 1993). Though the rate at which children experience bodily transformations may vary (i.e., maturity-associated variation), changes associated with puberty show age-related trends (Horn, 2015; Malina et al., 2004). Irrespective of maturity-associated variation (i.e., early, average, or late maturers) however, all youth will ultimately reach full physical maturation. Girls typically enter puberty around 10 to 11 years of age, whereas boys begin puberty around 12 to 13 years old. Girls also tend to reach full physical maturation before their male counterparts. Physical development leads to changes in anthropometric (e.g., height) and fitness (e.g., speed) characteristics of which adult leaders should be mindful to ensure that youth participants have the physiological capacity to meet the physical demands of an activity. As young people gain exposure to competitive contexts-which may increase those demands-adult leaders should evaluate whether or not activity participation is physically developmentally appropriate for youth to optimize their skill development, motivation, and well-being (Shah, 2009).

Adult leaders need a critical awareness of maturity-associated variation to inform expectations about and distribution of participation opportunities to youth-especially in competitive contexts. Youth who mature earlier relative to their chronological age can experience physical changes that advantage (or disadvantage) them given the demands of their task setting. For example, increasingly competitive youth sport programs may overlook late maturing male athletes and offer them fewer opportunities to develop competencies, despite their actual potential (Horn, 2015). Early physical maturation may have opposite effects for girls: social norms regarding sport proficiency tend to guide coaches/instructors to interpret physical changes that girls experience during puberty (e.g., development of breasts) as detrimental to athletic performance (Horn, Lox, \& Labrador, 2010). As such, adult leaders may limit early maturing females' opportunities to develop physical competencies and discourage competitive participation-especially in sports that advantage those with a linear build (e.g., gymnastics).

Children, however, are not miniature adults (Shields \& Bredemeier, 2009). Youth activity contexts (even if progressively competitive) should prioritize developing all participants' basic physical competencies. Growing trends to offer youth who appear talented because of physical 


\section{Competitive Readiness}

advantages (e.g., early maturers) participation opportunities in highly specialized sport programs may deny late maturers opportunities to develop fundamental skills. For the select group of youth specializing, such participation can also have deleterious long-term effects on intrinsic motivation, physical health, and well-being (Horn, 2015).

\section{Cognitive Maturation}

Knowledge of trends and variations in cognitive maturation can offer insight into how youth understand and experience competition throughout their developmental process. In particular, Nicholls' $(1984,1989)$ achievement goal perspective outlines one aspect of cognitive maturation salient to competitive readiness: how, and when, youth differentiate effort and ability. Nicholls posits that children conceive effort and ability as indices of competence, and highlights 7 to 12 years of age as developmentally relevant. Though young children may still be able to show concern over outperforming others, they are typically more self-oriented and task-involved. They equate effort with ability, and view task difficulty based on how easy the task is for them. Thus, young children are less preoccupied with how others are doing and more absorbed in their own learning and effort. Youth ages 7 to 8 years old may begin to differentiate effort from ability, but do so inconsistently. Their capacity to adopt a fully differentiated perspective develops as children cognitively mature (11 to 12 years old) (Weiss \& Williams, 2004). Youth understand that success requiring low effort implies high ability and that effort may enhance ability only up to an individual's personal capacity. They also use norm-referenced standards to judge task difficulty. At this developmental juncture, youth can choose to use undifferentiated or differentiated criteria to evaluate their ability.

Children's growing capacity to differentiate effort from ability has significant implications for how they understand competition and their competitive readiness process. Prior to age 7 , and even after this chronological marker, youth cannot reliably differentiate effort from ability. Youth with an undifferentiated (or partially differentiated) perspective who engage in activities that primarily use other-referenced criteria (e.g., beating the opponent) to measure success need these contexts (competitive or otherwise) to positively reinforce personal mastery and improvement (Nicholls, 1984, 1989). An emphasis on particular skills youth should execute when they put forth effort allows participants to maintain adaptive ability belief, and direction on how to work hard can help youth develop competence even without understanding that specific effortful demonstrations (more than others) can make up for ability discrepancies. As youth more consistently adopt a differentiated perspective, they also need a self-referenced, task-involved focus for a different developmental reason. Older youth, especially those low in 


\section{Competitive Readiness}

ability, need feedback on what strategies make effort fruitful to prevent learned helplessness and support development (Quested \& Duda, 2011; Theeboom, De Knop, \& Weiss, 1995).

\section{Psychosocial Maturation}

Knowledge of psychosocial maturation that youth experience between 7 and 12 years of age is useful to understand how youth appraise competitive contexts. Youth rely on different individuals for competence information depending on their developmental stage (Harter, 1999; Weiss \& Williams, 2004). Younger children (4 to 7 years old) conceive ability generally; however, as youth cognitively mature ( 7 to 12 years old) they begin to diversify their sources of competence information and use peer comparison and instructor/coach evaluative feedback instead of relying on parents to primarily inform self-appraisals of ability. Eventually, older children and adolescents (13 to 18 years old) use more self-referenced, self-regulated information to guide competency judgments (e.g., Horn, Glenn, \& Wentzell, 1993). As youth differentiate effort and ability and diversify sources of competence information, diversification of feedback improves accuracy of self-perceptions (Harter, 1999; Weiss, Bhalla, \& Price, 2008). In competitive contexts in which social comparison is inherent, other-referenced information can usefully inform a young person's assessment of his/her ability to help him/her identify personal strengths and areas for improvement. Thus, using social comparison information to measure relative ability can be valuable, and seeking to be "the best" among peers can be beneficial to youth in some circumstances (Passer, 1988; Shields \& Bredemeier, 2009).

Whether social comparison information is advantageous depends on why youth competitors want that information. When children want information in order to appear superior over others rather than for discovering new levels of personal excellence, an other-referenced orientation can undermine a focus on personal, task-specific goals necessary for improvement. Moreover, research in youth sport, music, and spelling contexts shows that dispositional tendencies (e.g., perfectionism) and climates that largely equate social comparison with success can thwart performance (Kenny \& Osbourne, 2006; J. Smith, 2013). Thus, youth need to prioritize improving over proving oneself, and adult leaders need to encourage adaptive uses of social comparison information (characteristic of mastery motivational climates) to better facilitate positive youth activity experiences. Robust research grounded in Nicholl's $(1984,1989)$ achievement goal theory show links between mastery-as a goal orientation and motivational climate-and adaptive youth psychosocial outcomes (detailed below and summarized in Table 1). 
Competitive Readiness

\section{Guiding Postulates for Competitive Readiness}

Organized activity leaders can help ensure that competition is advantageous for youth when they understand the individual, developmental needs of children. A developmental perspective that embraces each child as unique can allow youth to flourish through participation in competitive activities of varying intensities and frequencies. Considering this information, guiding postulates and their application to practice explained below can help practitioners promote positive youth development through competition.

\section{Couple Task-Specific Instruction With Encouragement to Support Personal Mastery Goals.}

In competitive contexts that reinforce performance outcomes to measure achievement, youth of all ability levels can experience personal success through use of self-referenced task goals (e.g., effort). Participants low in ability can feel a sense of personal accomplishment through learning and effort to support actual task mastery, rather than feeling inadequate relative to others. Participants high in ability can further develop actual (and perceived) competence through task goals for continued learning in spite of favorable social comparison. Research shows that youth athletes who focus on mastery and improvement experience lower performance anxiety, report higher levels of self-esteem, and participate for autonomous reasons (Kipp \& Amorose, 2008; Kipp \& Weiss, 2013, 2015; R. E. Smith, Smoll, \& Cumming, 2007; Theeboom et al., 1995).

\section{Application to Practice}

Given these findings, adult leaders involved in youth competitive activities can support a participant's development by offering task instruction and encouraging controllable aspects of the participant's performance. Specific, simple instruction can then help younger children grasp how to show effort to support learning, adaptive self-perceptions, and performance. Genuine encouragement can guard against children misinterpreting constructive criticism or non-verbal expressions as indicators of their inability, rather than advice for improvement (Dweck, 1999, 2006). For example, instructors can couple task-specific instruction with encouragement for unsuccessful effortful attempts with feedback such as, "Fantastic hustle on defense-if you cut inside next time, you'll be better positioned for the shot" in place of generic praise that undermines effort (e.g., "Too bad you didn't catch the attacker-almost!"). 


\section{Competitive Readiness}

\section{Promote Competitive Climates That Emphasize Improving Over Proving Oneself:}

Along with a young person's individual goal orientation, how an environment (motivational climate) defines and reinforces success is strongly tied to youth development (Duda, 2005; Nicholls, 1984, 1989). Youth who strongly perceive an activity context as supporting mastery are more likely to exhibit higher levels of self-esteem, intrinsic motivation, and enjoyment along with lower levels of performance anxiety relative to children with lower perceptions of a mastery climate (O'Rourke, Smith, Smoll, \& Cumming, 2014; R. E. Smith et al., 2007; Vazou, Ntoumanis, \& Duda, 2006). Though competitive contexts valuing social comparison do not necessarily have a negative impact, emphasis on results without attention to mastery can undermine youths' perceptions of control and task-relevant focus (Kipp \& Weiss, 2013, 2015). Overemphasis of peer comparison in competitive contexts with few "winners" may also produce artificially low ability perceptions that impede development (Horn \& Weiss, 1991). Such a climate can compel youth to disregard personal gains necessary for continued improvement, especially as youth become increasingly preoccupied with peer comparison. Relevant studies measuring youth perceptions of the coach-created motivational sport climate illuminate the impactful role that coaches and (potentially) other activity leaders can have in shaping how young people interpret competitive contexts (Cumming, Smoll, Smith, \& Grossbard, 2007).

In contrast, studies of youth activity participants, including but not limited to sports, illustrate how environments that exclusively promote winning as valuable (and losing as valueless) can detract from a focus on controllable aspects of performance and have negative developmental effects (Kipp \& Weiss, 2013, 2015; Smith, 2013). Thus, an environment that values mastery is especially important in competitive activities that use other-referenced criteria to define success for youth with low ability perceptions to support adaptive self-beliefs and participation motivation (Barnett, Smoll, \& Smith, 1992; Smoll et al., 1993).

\section{Application to Practice}

Given the significant influence that adult leaders have in creating the activity climate, they can leverage a young person's preoccupation for peer comparison to support their development by structuring activities for participants to give each other honest, positive reinforcement. Participants can pair up before practice sessions and provide positive feedback during training based on task goals that they select. Doing so grants youth choice, and can build peer relatedness and competence on task-relevant skills. Parents and youth also contribute to whether activity contexts facilitate youth development (Keegan, Spray, Harwood, \& Lavalee, 2010). They can positively reinforce mistakes as learning opportunities; in doing so, youth are 


\section{Competitive Readiness}

more likely to take risks to develop competencies rather than worry about appearing superior. Instead of limiting positive reinforcement to successful performances, parents can use failureas-necessary feedback such as, "I loved that you tried that new skill. Taking risks can help you improve!"

\section{Provide Autonomy Support Through Adult-Youth Interpersonal Interactions.}

Competence, autonomy, and relatedness are universal, psychological needs relevant to a child's competitive readiness process (Deci \& Ryan, 2008). Youth who experience satisfaction of basic needs are more self-determined in their motivation. Youth who engage in activities for more autonomous (e.g., fun) and less controlling (e.g., external rewards) motives exhibit higher levels of self-determined motivation, and are more likely to experience personal growth and enhanced well-being relative to those participating for controlling reasons. Adult leaders can satisfy athletes' psychological needs through an autonomy-supportive approach (Amorose \& Anderson-Butcher, 2007; Kipp \& Weiss, 2013). Autonomy support refers to child-directed actions that show genuine, equal care for all participants, and offer them choice and agency.

\section{Application to Practice}

Especially in highly competitive contexts that are inherently externally rewarding and controlling, adult leaders can be autonomy-supportive to foster self-determined youth. First, parents should ask children if they want to participate in activities, competitive or otherwise, to offer them choice. Second, adult leaders can acknowledge a young person's feelings and shift responsibility to children to promote self-determined motivation. Shifting responsibility to youth means allowing them to solve problems and make decisions in developmentally appropriate ways. Simple, concrete opportunities to make decisions are more suitable for younger children. Older adolescents are more cognitively capable of more abstract and less egocentric reasoning in competitive play and interpersonal interactions, and thus are likely better able to handle complex decisions. Contrastingly, controlling adult leaders who rely on external rewards and offer overly critical, controlling feedback, can inhibit needs satisfaction to thwart selfdetermined motivation (Kipp \& Amorose, 2008; Reinboth \& Duda, 2006).

\section{Facilitate Inclusive, Cooperative Peer Interactions.}

Integration of cooperation into competitive contexts can further support youth psychological needs by bolstering adaptive self-perceptions. Associations between competitive tasks and adaptive self-perceptions and motivation are mixed among youth. Some studies have shown 


\section{Competitive Readiness}

that competition can enhance performance and intrinsic motivation, especially in youth with high ability perceptions. Other studies evidence that competition undermines performance (J. Smith, 2003) and leads to lower perceptions of social support and self-concept (Marsh \& Peart, 1988; Tauer \& Harackiewicz, 2004). In contrast, cooperative activity programs have been linked to favorable self-perceptions-particularly among girls (Gibbons, Ebbeck, Concepcion, \& Li, 2010; Marsh \& Peart, 1988). Equivocal findings on facilitative effects of competition and cooperation have implications for youth competitive readiness. For kids who increasingly engage in competition, integration of cooperative tasks may buffer negative self-perceptions and support development (Daniels, 2007; Shields \& Bredemeier, 2009). Such an approach may enable youth to experience the benefits of competition and cooperation to optimally grow through participation.

\section{Application to Practice}

Adult leaders should also create opportunities for inclusive peer interactions to strengthen feelings of social support and enhance needs satisfaction. Youth participants who feel a sense of belonging from significant others are more likely to persist through challenges, possess higher levels of self-esteem, and experience improved well-being (Kipp \& Weiss, 2013, 2015). For example, leaders can structure peer modeling activities for youth to help their peers build positive self-perceptions within competitive settings. When learners identify their model as a peer, they can enhance attention to task-relevant cues and self-efficacy beliefs (McCullagh \& Weiss, 2002; Weiss, Ebbeck, \& Wiese-Bjornstal, 1993). During adolescence when peers serve as a primary source from which youth derive feelings of belonging, peer relatedness can enhance development and well-being (A. L. Smith, 2003).

Adult leaders should consider gradually integrating cooperative competition into youth participation contexts. Activities can start with individual, mastery-oriented tasks (that combine work with another peer) and become increasingly cooperative as youth acquire physical and cognitive capabilities to perform complex, team-oriented challenges. For example, an instructor can organize activities that encourage youth to work through challenges with teammates and compete without undercutting social support by narrating how competing can serve team unity.

\section{Cultivate Activity Experiences That Develop Excitement and a Breadth of Basic Skills.}

Two aspects of an activity experience are particularly relevant to a young person's competitive readiness process: excitement and a breadth of basic skills. First, children should be able to 
Competitive Readiness

participate in activities about which they are excited and passionate. To ensure that children want to play-and compete-adults should consider a child's motivational readiness, realizing that a "ready" state regards more than skill proficiency or physical capacity (Dockett \& Perry, 2002; Petho, 2017). For youth in early childhood, competition does not need to be entirely excluded, but adult leaders should de-emphasize performance outcomes in favor of fostering enjoyment and passion for participation (Côté, 1999).

\section{Application to Practice}

Instructors and parents can provide youth with engaging environments at varying competitive levels by structuring optimal challenges. Adult leaders who have knowledge of a child's physical competence can design optimal challenges for youth participants, which are particularly beneficial for kids low in perceived competence who are likely to avoid challenges (Smoll et al., 1993; Stuntz \& Weiss, 2010). Such challenges are difficult but realistic tasks that enhance selfperceptions, affect, and intrinsic motivation when youth experience success. These outcomes make youth more likely to engage in an activity and future attempts (Weiss \& Williams, 2004). Empowered with skills and intrinsic desire to participate, youth-in conversation with parentscan chart a developmental course that aligns with their passions/ambitions. For example, leaders can design training "activities/games" rather than "drills" that maximize active involvement to facilitate mastery and intrinsic motivation. A gradual progression of task difficulty enables youth to build on initial successes to accomplish optimal challenges. Coaches/instructors can modify training activities and use realistic game restrictions to control task difficulty.

Activities should also afford all youth varied participation experiences to develop a breadth of basic skills. Growing trends to specialize youth into one activity early, and selection of those who appear talented only develop select youth and skill sets. Not only do few youth who specialize "make it" to elite levels, but an overwhelming number eventually drop out (Malina, 2010). Moreover, youth have unique needs: they need to grow biologically and develop behaviorally. They should have opportunities to explore activities in order to acquire diverse, fundamental skills and experiences that support holistic well-being. Balance between breadth and intensity across competitive, or otherwise, activity contexts is crucial for linked, organizational programming efforts for PYD promotion (Busseri \& Rose-Krasnor, 2009). After exploring a range of activities, young people can then choose to pursue activities that support their interests. 


\section{Application to Practice}

Parents can provide youth with opportunities to engage in diverse activities between ages 6 and 12 (i.e., sampling years; Côté, 1999). Côté and colleagues' collective body of research highlights the psychosocial benefits of exposure to varied activity contexts in early to middle childhood (Côté, Lidor, \& Hackfort, 2009; Côté \& Viermiaa, 2014). Likewise, organizations need to support this exploratory period through seasonally-limited training/competition so that youth have time to participate in other extracurricular pursuits.

\section{Understand Competitive Readiness as an Ongoing, Individual Process.}

Competitive readiness is an ongoing process that encompasses a child's individual needs in relation to personal, contextual, and developmental influences. Interacting factors impact fluctuations in a young person's state of competitive readiness at any given time. A processoriented understanding of competitive readiness is important for youth to positively develop through competition regardless of their chronological age or developmental stage (Benson et al., 2006; Passer, 1988). Motivational and cognitive factors are important to evaluate a young person's growing capacity to thrive through competitive experiences. Young children may be less capable of adaptively dealing with competition: self-referential tendencies of children under age 7 may impede their ability to adaptively process performance feedback (e.g., results and instruction) in competition (Nicholls 1984, 1989; Passer, 1988). At best, younger children may simply maintain their individualistic focus-thus making social comparison inherent in competition irrelevant. Without the capacity to differentiate and role-take, children may not fully grasp underlying causes of competitive outcomes. They may fail to account for influential external factors or aspects of performance that require more (or less) effort for a favorable outcome.

\section{Application to Practice}

Adults should avoid compelling children younger than 7 to compete, provided they follow agerelated maturational trends (Passer, 1988). Adults can gradually transition youth into competitive activities as youth show motivational and cognitive readiness (ages 7 to 12), while mindful that cognitive maturation is varied and incremental. Importantly, cognitive maturity does not make older adolescents (or adults) immune to deleterious effects of competition or misinterpretation of feedback (Passer, 1988). Older adolescents may seem "ready", but competition may actually undermine development and well-being when other stressors tip them out of a state of readiness. For example, external stressors such as lack of social support, highly rigorous training, and pressure to succeed, can shift an individual out of a "ready" state. Thus, 
Competitive Readiness

when youth and adult leaders understand competitive readiness as an ongoing, individual process, they can better ensure that frequency and intensity of exposure to competition adjust based on each child's needs.

Table 1. Postulates, Take-Home Messages, and Applications to Practice for Youth Competitive Readiness

\begin{tabular}{|c|c|c|}
\hline Postulate & Take-home message & Application to practice \\
\hline $\begin{array}{l}\text { 1. Couple task-specific instruction } \\
\text { with encouragement to support } \\
\text { personal mastery goals in youth } \\
\text { participants of varying ability. }\end{array}$ & $\begin{array}{l}\text { Participants low in ability can } \\
\text { experience success through task } \\
\text { mastery instruction. } \\
\text { Participants high in ability can } \\
\text { experience competence through } \\
\text { task goals for continued learning. }\end{array}$ & $\begin{array}{l}\text { Instructional example: "Fantastic } \\
\text { hustle on defense! If you cut inside } \\
\text { next time, you'll be in position for } \\
\text { the shot," instead of generic praise } \\
\text { that undermines effort (e.g., "You } \\
\text { almost caught the forward!") }\end{array}$ \\
\hline $\begin{array}{l}\text { 2. Promote competitive climates } \\
\text { that emphasize improving over } \\
\text { proving oneself-especially as youth } \\
\text { become increasingly preoccupied } \\
\text { with peer comparison. }\end{array}$ & $\begin{array}{l}\text { Encourage mastery over competitive } \\
\text { outcomes and social comparisons in } \\
\text { order to enhance youth levels of } \\
\text { self-esteem, intrinsic motivation, } \\
\text { and enjoyment. }\end{array}$ & $\begin{array}{l}\text { Instructional example: "I love how } \\
\text { you tried that new skill. Risk-taking } \\
\text { can help you improve!" }\end{array}$ \\
\hline $\begin{array}{l}\text { 3. Provide autonomy support } \\
\text { through adult-youth interpersonal } \\
\text { interactions. }\end{array}$ & $\begin{array}{l}\text { Show genuine, equitable care for all } \\
\text { participants, and give them choice } \\
\text { and agency. }\end{array}$ & $\begin{array}{l}\text { Have youth think about and } \\
\text { demonstrate a recently learned skill } \\
\text { of their choice at the start of } \\
\text { practice. }\end{array}$ \\
\hline $\begin{array}{l}\text { 4. Facilitate inclusive, cooperative } \\
\text { peer interactions. }\end{array}$ & $\begin{array}{l}\text { Create opportunities for youth peers } \\
\text { to offer social support to enhance } \\
\text { youth self-perceptions. }\end{array}$ & $\begin{array}{l}\text { Instructional example: "We are } \\
\text { working hard against one another in } \\
\text { practice today because challenging } \\
\text { each other will help us raise our } \\
\text { game!" }\end{array}$ \\
\hline $\begin{array}{l}\text { 5. Cultivate sport experiences that } \\
\text { develop excitement and a breadth } \\
\text { of basic skills. }\end{array}$ & $\begin{array}{l}\text { Use games and activities to } \\
\text { maximize fun and active } \\
\text { engagement of various skills. }\end{array}$ & $\begin{array}{l}\text { Structure practices with shorter } \\
\text { lines and lectures to maximize } \\
\text { active engagement in training. }\end{array}$ \\
\hline $\begin{array}{l}\text { 6. Understand competitive readiness } \\
\text { as an ongoing, individual process. }\end{array}$ & $\begin{array}{l}\text { Be responsive to youth, regardless } \\
\text { of age, by considering internal and } \\
\text { external stressors that they may } \\
\text { experience during participation in } \\
\text { competitive activities. }\end{array}$ & $\begin{array}{l}\text { Openly communicate with youth } \\
\text { about perceptions of their } \\
\text { experience and desired participation } \\
\text { in competitive activity contexts. }\end{array}$ \\
\hline
\end{tabular}




\section{Conclusion}

Youth are "ready" to compete not just when they can survive, but thrive in competitive contexts. Thriving through competition: (a) requires aligning the features of the competitive activity context with the needs and capacities of youth (i.e., person-context "fit"), and (b) is expressed through mutually-derived, ongoing benefit for the youth in their activity context. A developmental perspective highlights the critical age range (ages 7 to 12) during which youth typically experience significant maturational changes relevant to their competitive readiness process. Empirical work in sport, and other, performance domains highlight personal, contextual, and developmental conditions under which youth can flourish through competition. Considering the literature, we argue for adult (and youth) leaders to shift their thinking about competition: more than an adverse experience that prepares (or hardens) youth to harsher realities of adulthood, competition can be an intentional tool, used by practitioners to promote thriving. That is, competition can promote positive youth development. Research-informed postulates and examples address how activity leaders can better ensure that youth are ready for and empowered through competition.

\section{References}

Aicinena, S. (1992). Youth sport readiness: A predictive model for success. ProQuest, 49, 58-66.

Amorose, A. J., \& Anderson-Butcher, D. (2007). Autonomy-supportive coaching and self-determined motivation in high school and college athletes: A test of self-determination theory. Psychology of Sport and Exercise, 8(5), 654-670. doi:10.1016/j.psychsport.2006.11.003

Barnett, N. P., Smoll, F. L., \& Smith, R. E. (1992). Effects of enhancing coach-athlete relationships on youth sport attrition. The Sport Psychologist, 6(2), 111-127. doi:10.1123/tsp.6.2.111

Benson, P. L., \& Scales, P. C. (2009). The definition and preliminary measurement of thriving in adolescence. Journal of Positive Psychology, 4(1), 85-104. doi:10.1080/17439760802399240

Benson, P. L., Scales, P. C., Hamilton, S. F., \& Sesma, A. (2006). Positive youth development: Theory, research, and applications. In W. Damon \& R. M. Lerner (Eds.), Handbook of child psychology. Vol. 1: Theoretical models of human development (6 $6^{\text {th }}$ ed., pp. 894-941). New York, NY: Wiley.

Bowers, E. P., Geldhof, G. J., Johnson, S. K., Lerner, J. V., \& Lerner, R. M. (2014). Special issue introduction: Thriving across the adolescent years: A view of the issues. Journal of Youth and Adolescence, 43(6), 859-868. doi:10.1007/s10964-014-0117-8 


\section{Competitive Readiness}

Busseri, M. A., \& Rose-Krasnor, L. (2009). Breadth and intensity: Salient, separable, and developmentally significant dimensions of structured youth activity involvement. British Journal of Developmental Psychology, 27, 907-933. doi:10.1348/026151008X397017

Choi, H. S., Johnson, B., \& Kim, Y. K. (2014). Children's development through sports competition: Derivative, adjustive, generative, and maladaptive approaches. Quest, 66(2), 191-202. doi:10.1080/00336297.2013.861757

Coakley, J. (2011). Youth sports: What counts as "positive development"? Journal of Sport and Social Issues, 35(3), 306-324. doi:10.1177/0193723511417311

Côté, J. (1999). The influence of the family in the development of talent in sport. The Sport Psychologist, 13(4), 395-417. doi:10.1123/tsp.13.4.395

Côté, J., Lidor, R., \& Hackfort, D. (2009). ISSP position stand: To sample or to specialize? Seven postulates about youth sport activities that lead to continued participation and elite performance. International Journal of Sport and Exercise Psychology, 7(1), 7-17. doi:10.1080/1612197X.2009.9671889

Côté, J., \& Viermiaa, M. (2014). The developmental model of sport participation: 15 years after its first conceptualization. [Supplement]. Science \& Sports, 29, S63-S69. doi:10.1016/j.scispo.2014.08.133

Cumming, S. P., Smoll, F. L., Smith, R. E., \& Grossbard, J. R. (2007). Is winning everything? The relative contributions of motivational climate and won-lost percentage in youth sports. Journal of Applied Sport Psychology, 19(3), 322-336. doi:10.1080/10413200701342640

Damon, W. (2004). What is positive youth development? Annals of the American Academy of Political and Social Science, 591(1), 13-24. doi:10.1177/0002716203260092

Daniels, A. M. (2007). Cooperation versus competition: Is there really such an issue? New Directions for Youth Development, 115, 43-56. doi:10.1002/yd.222

Diener, E. (2009). Positive psychology: Past, present, and future. In C. R. Snyder \& J. L. Lopez (Eds.), Oxford handbook of positive psychology (pp. 7-11). Oxford, UK: Oxford University Press. doi:10.1093/oxfordhb/9780195187243.013.0002

Deci, E. L., \& Ryan, R. M. (2008). Self-determination theory: A macrotheory of human motivation, development, and health. Canadian Psychology, 49, 182-185. doi:10.1037/a0012801

Dockett, S. \& Perry, B. (2002). Who's ready for what? Young children starting school. Contemporary Issues in Early Childhood, 3(1), 67-89. doi:10.2304/ciec.2002.3.1.9

Duda, J. L. (2005). Motivation in sport: The relevance of competence and achievement goals. In A. J. Elliot \& C. S. Dweck (Eds.), The handbook of competence and motivation (pp. 318-335). New York, NY: Guilford Press.

Dweck, C. S. (1999). Self-theories: Their role in motivation, personality, and development. Philadelphia, PA: Psychology Press. 


\section{Competitive Readiness}

Dweck, C. S. (2006). Mindset: The new psychology of success. New York, NY: Random House.

Eccles, J. S., Barber, B. L., Stone, M., \& Hunt, J. (2003). Extracurricular activities and adolescent development. Journal of Social Issues, 59(4), 865-889. doi:10.1046/j.0022-4537.2003.00095.x

Eccles, J. S., \& Gootman, J. A. (2002). Community programs to promote youth development. Washington, DC: National Academy Press.

Fraser-Thomas, J. L., Côté, J., \& Deakin, J. (2005). Youth sport programs: An avenue to foster positive development. Physical Education and Sport Pedagogy, 10, 19-40.

Friedman, H. L. (2013). Playing to win: Raising children in a competitive culture. Berkeley, CA: University of California Press.

Gibbons, S. L., Ebbeck, V., Concepcion, R. Y., \& Li, K. (2010). The impact of an experiential education program on the self-perceptions and perceived social regard of physical education students. Journal of Sport \& Exercise Psychology, 32(6), 786-804. doi:10.1123/jsep.32.6.786

Gould, D. (2009). The professionalization of youth sports: It's time to act! Clinical Journal of Sports Medicine, 19(2), 81-82. doi:10.1097/JSM.0b013e31819edaff

Gould, D., \& Carson, S. (2008). Life skills development through sport: current status and future directions. International Review of Sport and Exercise Psychology, 1, 58-78. doi:10.1080/17509840701834573

Hamilton, S. F., Hamilton, M. A., \& Pittman, K. (2004). Principles for youth development. In S. F. Hamilton \& M. A. Hamilton (Eds.), The youth development handbook: Coming of age in American communities (pp. 3-22). Thousand Oaks, CA: Sage.

Harris, S. (2000). Readiness to participate in sports. In J. A. Sullivan \& S. J. Anderson (Eds.), Care of the young athlete. Rosemont, IL: American Academy of Orthopedic Surgeons, American Academy of Pediatrics.

Harter, S. (1999). The construction of the self: A developmental perspective. New York, NY: Guilford Press.

Horn, T. S. (2015). Social and psychological developmental perspectives on early sport specialization. Kinesiology Review, 4(3), 248-266. doi:10.1123/kr.2015-0025

Horn, T. S., Glenn, S. D., \& Wentzell, A. B. (1993). Sources of information underlying personal ability judgment in high school athletes. Pediatric Exercise Science, 5(3), 263-274. doi:10.1123/pes.5.3.263

Horn, T. S., Lox, C. L., \& Labrador, F. (2010). The self-fulfilling prophecy theory: When coaches' expectations become reality. In J. M. Williams (Ed.), Applied sport psychology: Personal growth to peak performance (pp. 82-108). New York, NY: McGraw-Hill.

Horn, T. S., \& Weiss, M. R. (1991). A developmental analysis of children's self-ability judgments in the physical domain. Pediatric Exercise Science, 3(4), 310-326. doi:10.1123/pes.3.4.310 


\section{Competitive Readiness}

Keegan, R. J., Spray, C. M., Harwood, C. G., \& Lavallee, D. E. (2010). The motivational atmosphere in youth sport: Coach, parent and peer influences on motivation in specializing sport participants. Journal of Applied Sport Psychology, 22(1), 87-104. doi:10.1080/10413200903421267

Kenny, D. T., \& Osborne, M. S. (2006). Music performance anxiety: New insights from young musicians. Advances in Cognitive Psychology, 2(2), 103-112. doi:10.2478/v10053-008-0049-5

Kipp, L. E., \& Amorose, A. J. (2008). Perceived motivational climate and self-determined motivation in female high school athletes. Journal of Sport Behavior, 31(2), 108-129.

Kipp, L. E., \& Weiss, M. R. (2013). Social influences, psychological need satisfaction, and well-being among female adolescent gymnasts. Sport, Exercise, and Performance Psychology, 2(1), 62-75. doi:10.1037/a0030236

Kipp, L. E., \& Weiss, M. R. (2015). Social predictors of psychological need satisfaction and well-being among female adolescent gymnasts: A longitudinal analysis. Sport, Exercise, and Performance Psychology, 4(3), 153-169. doi:10.1037/spy0000033

Kohn, A. (1992). No contest: The case against competition. Boston, MA: Houghton Mifflin.

Larson, R. (2000). Toward a psychology of positive youth development. American Psychologist, 55(1), 170-183. doi:10.1037//0003-066X,55.1.170

Lerner, R. M., Lerner, J. V., Almerigi, J., Theokas, C., Naudeau, S., Gestsdottir, S., . . von Eye, A. (2005). Positive youth development, participation in community youth development programs, and community contributions of fifth-grade adolescents: Findings from the first wave of the 4-H Study on positive youth development. Journal of Early Adolescence, 25(1), 17-71. doi: $10.1177 / 0272431604272461$

Mahoney, J. L., Larson, R. W., Eccles, J. S., \& Lord, H. (2005). Organized activities as developmental contexts for children and adolescents. In J. L. Mahoney, R. W.Larson, \& J. S. Eccles (Eds.), Organized activities as contexts for development: Extracurricular activities, after-school and community programs (pp. 3-22). Mahwah, NJ: Lawrence Erlbaum Associates.

Malina, R. M. (2010). Early sport specialization: Roots, effectiveness, and risks. Current Sport Medicine Reports, 9(6), 364-371. doi:10.1249/JSR.0b013e3181fe3166

Malina, R.M., Bouchard, C., \& Bar-Or, O. (2004). Growth, maturation, and physical activity. Champaign, IL: Human Kinetics.

Marsh, H. W., \& Peart, N. D. (1988). Competitive and cooperative physical fitness training programs for girls: Effects on physical fitness and multidimensional self-concepts. Journal of Sport \& Exercise Psychology, 10(4), 390-407. doi:10.1123/jsep.10.4.390

Martens, R., \& Gill, D. L. (1976). State anxiety among successful and unsuccessful competitors who differ in competitive trait anxiety. Research Quarterly, 47(4), 698-708. doi:10.1080/10671315.1976.10616731 


\section{Competitive Readiness}

McCullagh, P., \& Weiss, M. R. (2002). Observational learning: The forgotten psychological method in sport psychology. In J. L. Van Raalte \& B. W. Brewer (Eds.), Exploring sport and exercise psychology (2 ${ }^{\text {nd }}$ ed.). Washington, DC: American Psychological Association.

National Research Council and Institute of Medicine. (2002). Community programs to promote youth development. Washington, DC: National Academy Press.

Nicholls, J. G. (1984). Achievement motivation: Conceptions of ability, subjective experience, task choice, and performance. Psychological Review, 91(3), 328-346. doi:10.1037/0033-295X.91.3.328

Nicholls, J. G. (1989). The competitive ethos and democratic education. Cambridge, MA: Harvard University Press.

O'Rourke, D. J., Smith, R. E., Smoll, F. L., \& Cumming, S. P. (2014). Relations of parent- and coachinitiated motivational climate to youth athletes' self-esteem, performance anxiety, and autonomous motivation: Who is more influential? Journal of Applied Sport Psychology, 26(4), 395-408. doi:10.1080/10413200.2014.907838

Passer, M. W. (1988). Psychological issues in determining children's age-readiness for competition. In F. L. Smith \& R. A. Magill, \& M. J. Ash (Eds.), Children and youth in sport (3 $3^{\text {rd }}$ ed., pp. 67-77). Campaign, IL: Human Kinetics.

Petho, D. A. (2017). The performance success within the competitive equestrian field: A novice and intermediate rider focused investigation. Journal of Human Sport and Exercise, 12(3proc), S857S871. doi:10.14198/jhse.2017.12.Proc3.10

Petitpas, A. J., Cornelius, A. E., Van Raalte, J. L., \& Jones, T. (2005). A framework for planning youth sport programs that foster psychosocial development. The Sport Psychologist, 19(1), 63-80. doi:10.1123/tsp.19.1.63

Quested, E., \& Duda, J. L. (2011). Antecedents of burnout among elite dancers: A longitudinal test of basic needs theory. Psychology of Sport and Exercise, 12(2), 159-167. doi:10.1016/j.psychsport.2010.09.003

Reinboth, M., \& Duda, J. L. (2006). Perceived motivational climate, need satisfaction and indices of wellbeing in team sports: A longitudinal perspective. Psychology of Sport and Exercise, 7(3), 269286. doi:10.1016/j.psychsport.2005.06.002

Scanlan, T. K. (1996). Social evaluation and the competition process. In F. L. Smith \& R. E. Smoll (Eds.), Children and youth in sport: A biopsychosocial perspective (pp. 298-308). Madison, WI: Brown \& Benchmark.

Scanlan, T. K., \& Lewthwaite, R. (1984). Social psychological aspects of competition for male youth sport participants: Predictors of competitive stress. Journal of Sport Psychology, 6(2), 208-226. doi:10.1123/jsp.6.2.208

Scanlan, T. K., \& Passer, M. W. (1978). Factors related to competitive stress among male youth sport participants. Medicine and Science in Sports, 10(2), 103-108. 


\section{Competitive Readiness}

Scanlan, T. K., \& Passer, M. W. (1979). Sources of competitive stress in young female athletes. Journal of Sport Psychology, 1(2), 151-159. doi:10.1123/jsp.1.2.151

Shah, S. (2009). Determining a young dancer's readiness for dancing on pointe. American College of Sports Medicine, 8(6), 295-299. doi:10.1249/JSR.0b013e3181c1ddf1

Shields, D. L. \& Bredemeier, B. L. (2009). True competition: A guide to pursuing excellence in sport and society. Champaign, IL: Human Kinetics.

Simon, J. A., \& Martens, R. (1979). Children's anxiety in sport and non-sport evaluation activities. Journal of Sport Psychology, 1(2), 160-169. doi:10.1123/jsp.1.2.160

Smith, A. L. (2003). Peer relationships in physical activity contexts: A road less traveled in youth sport and exercise psychology research. Psychology of Sport and Exercise, 4(1), 25-39. doi:10.1016/S1469-0292(02)00015-8

Smith, J. (2013). Peers, pressure, and performance at the national spelling bee. Journal of Human Resources, 48(2), 265-285. doi:10.3368/jhr.48.2.265

Smith, R. E., Smoll, F. L., \& Cumming, S. P. (2007). Effects of a motivational climate intervention for coaches on young athletes' sport performance anxiety. Journal of Sport \& Exercise Psychology, 29(1), 39-59. doi:10.1123/jsep.29.1.39

Smith, R. E., Smoll, F. L., \& Curtis, B. (1979). Coach effectiveness training: A cognitive-behavioral approach to enhancing relationship skills in youth sport coaches. Journal of Sport Psychology, 1(1), 59-75. doi:10.1123/jsp.1.1.59

Smoll, F. L., Smith, R. E., Barnett, N. P., \& Everett, J. J. (1993). Enhancement of children's self-esteem through social support for youth sport coaches. Journal of Applied Psychology, 78(4), 602-610. doi:10.1037/0021-9010.78.4.602

Stuntz, C. P., \& Weiss, M. R. (2010). Motivating children and adolescents to sustain a physically active lifestyle. American Journal of Lifestyle Medicine, 4(5), 433-444. doi:10.1177/1559827610368779

Tauer, J. M. \& Harackiewicz, J. M. (2004). The effects of cooperation and competition on intrinsic motivation and performance. Interpersonal Relations and Group Processes, 86(6), 849-861. doi:10.1037/0022-3514.86.6.849

Theeboom, M., De Knop, P., \& Weiss, M. R. (1995). Motivational climate, psychological responses, motor skill development in children's sport: A field-based intervention study. Journal of Sport \& Exercise Psychology, 17(3), 294-311. doi:10.1123/jsep.17.3.294

Vazou, S., Ntoumanis, N., \& Duda, J. L. (2006). Predicting youth athletes' motivational indices as a function of their perceptions of the coach- and peer-created climate. Psychology of Sport and Exercise, 72 ), 215-233. doi:10.1016/j.psychsport.2005.08.007

Weiss, M. R., Bhalla, J. A., \& Price, M. S. (2008). Developing positive self-perceptions through youth sport participation. In H. Hebestreit \& O. Bar-Or (Eds.), The young athlete (pp. 302-318). Malden, MA: Blackwell Publishing. 
Journal of Youth Development | http://jyd.pitt.edu/ | Vol. 14 Issue 1 DOI 10.5195/jyd.2019.671

Competitive Readiness

Weiss, M. R., Ebbeck, V., \& Wiese-Bjornstal, D. M. (1993). Developmental and psychological skills related to children's observational learning of physical skills. Pediatric Exercise Science, 5(4), 301-317. doi:10.1123/pes.5.4.301

Weiss, M. R., \& Williams, L. (2004). The why of youth sport involvement: A developmental perspective on motivational processes. In M. R. Weiss (Ed.), Developmental sport and exercise psychology: $A$ lifespan perspective (pp. 223-268). Morgantown, WV: Fitness Information Technology, Inc. 